СОЦИОЛОГИЯ ИДЕНТИЧНОСТИ ЭРИХА Х. ЭРИКСОНА: ГНОСЕОЯОГИЧЕСКИЕ ВОЗМОЖНОСТИ И СОДЕРЖАТЕДЬНЫЕ ГРАНИЦЫ

\title{
SOCIOLOGY OF IDENTITY OF ERICH H. ERIKSON: GNOSEOLOGICAL POSSIBILITIES AND CONTENT BOUNDARIES
}

\section{ПОЛЕЖАЕВ Дмитрий В Аадимирович}

Волгоградская государственная академия последипломного образования,

Волгоград, Россия

E-mail: polezh@mail.ru

Аннотация. В статье рассматривается феномен идентичности в представлении Э. Эриксона через призму соцчологии, соцчильной психологии и философии. Предложенные Э. Эриксоном виды идентичности раскрываются через их содержательные характеристики и социиальную роль.

В контексте теории кризиса идентичности автором предлагаются для осмысления факторы влияния на становление личности в сочиальном пространстве. Идентификация понимается как процесс непрерывного сопоставления себл субъектали соииальной действи тельности (индивид, социальная группа, большое человеческое сообщество) с другими субъектами. Социальная идентичность представляется автором как открытый процесс, продолжающийся в контексте конкретного социиально-культурного пространства.

Через призму ментального подхода к осмыслению проблем взаимодействия общества и человека определень гносеологические возможности и содержательные гранииь социологии Эриха Х. Эриксона в осмыслении феномена идентичности как социально-индивидуального феномена.

Ключевые слова: социология, идентичность, психоанализ, философия, соииальная психология, ментальность, ментальный подход.

\section{POLEZHAYEV Dmitry V.}

Volgograd State Academy of Postgraduate Education, Volgograd, Russia

E-mail: polezh@mail.ru

Abstract. The article examines the phenomenon of identity in the view of E. Erickson, through the prism of sociology, social psychology and philosophy. The types of identity proposed by Erickson are revealed through their content characteristics and social role.

In the context of the theory of the identity crisis, the author proposes for understanding the factors of influence on the formation of a personality in social space. Identification is understood as a process of continuous comparison of themselves by the subjects of social reality (individual, social group, large human community) with other subjects. Social identity is presented by the author as an open process that continues in the context of a specific socio-cultural space.

Through the prism of a mental approach to understanding the problems of interaction between society and a person, the epistemological possibilities and content boundaries of Erich H. Erickson's sociology in understanding the phenomenon of identity as a socially individual phenomenon are determined.

Keywords: sociology, identity, psychoanalysis, philosophy, social psychology, mentality, mental approach.

Введение. Содержательная детерминация феномена идентичности в социологическом или социально-философском ключе не может не включать в себя психологическую компоненту, поскольку социальные феномены рассматриваются исследователями преимущественно через призму взаимодействия дичности с присущими ей психологическими характеристиками

() Полежаев Д. В., 2021. 
и чертами, возрастными и иными особенностями, с окружающим социальным миром.

Идентичность как социальный феномен (это в полной мере касается также гражданской и исторической идентичности) не может быть исчерпывающе развернута в исследовательском и даже просто в дескриптивном ключе с опорой только на психологическое знание. Тем не менее ряд исследователей, в том числе авторов программ воспитания и развития личности, ориентированных на реализацию государственных стандартов современного российского образования в отношении новых поколений россиян (Данилюк, Кондаков, Тишков 2009), довольствуются дишь психологическим подходом в анадизе и определении идентичности.

И. Ю. Николаева, признавая Э. Эриксона автором теории идентичности, раскрывшим в ней наиболее убедительно сущностные аспекты и социально-индивидуальные стороны проявления рассматриваемого феномена, подчеркивает, тем не менее, недостаточность в осмыслении его искдючитедьного психологического подхода. «Анализ идентичности, - пишет она, может приобрести формат большей строгости при использовании инструментария теории установки Д. Н. Узнадзе» (2014:117). Данная мысль видится важной при рассмотрении идентичности как социального феномена, то есть в контексте взаимодействия личности и общества в условиях наличной культуры.

В социологии идентичности Э. Эриксона идентичность понимается как «тождество самому себе» в непрерывности индивидуального существования в пространстве и времени, и именно в единстве трех временных модальностей, что подчеркивал в свое время М. А. Барг (1987:7), а также в социальном окружении, прежде всего, ближайшем, на признание которого в первую очередь ориентируется становящаяся личность. Такое определение идентичности видится автору статьи вполне уместным, поскольку в нем представлен личностно-социальный аспект феномена в историческом протяжении (Эриксон 1996).

Э. Эриксон определил для личности три основных вида идентичности: позитивную, негативную и смешанную. Предложенный вариант классификации вполне убедителен, но и он небезупречен, поскольку содержание его имеет явную психологическую окраску. А это не совпадает с нашим пониманием идентичности, которое в контексте ментального функционирования феномена имеет глубинно-психологическую природу, но не эмоциональнопсихологическую и, тем более, не психоаналитическую, которая и превалирует в концепции Эриксона.

Позитивная идентичность, по Э. Эриксону, представляет собой внутренне непротиворечивую интериоризацию социокультурных нормативов окружающего мира. В качестве основы ее осуществления Э. Эриксон говорит о психологической уверенности человека в себе; а с точки зрения автора статьи концепции ментальности дичности в тоталитарном обществе (Полежаев 2007) - это характеристика тоталитарного индивида, некритически принимающего все извне направленные воздействия. В этом - главное про- 
тиворечие и главная же опасность такого рода личностного самоопредедения: самые раздичные, даже крайне противоречивые, векторы индивидуальной самоидентификации в социуме сливаются для некритически ориентированного сознания воедино. А это - не просто противоречие, это взрыв, ценностный, поведенческий, нравственный, социальный.

Такого рода аспекты важно учитывать с точки зрения индивидуадьноличностного самоопределения (самоидентификации). Однако в абстрактнонаучном измерении (понимании проблемы идентичности «вообще») такие аспекты проблемы часто упускают из виду. Противоречия в сопряжении разнонаправленных ментальных установок действия / поведения приводят к кризису не только индивидуального сознания, но и сознания коллективного и даже в определенном смысле «самосознания эпохи» (Барг 1987). Выработка новых установок восприятия, оценки и поведения - ориентир (своего рода программа) выхода из кризиса. Установочные механизмы личностносоциального самоопределения, в контексте системы Д. Н. Узнадзе, видятся важным элементом методологической основы социально-индивидуального функционирования ментального плана, что подчеркивалось ранее автором (Подежаев 2018) и другими отечественными исследователями - специадистами в сфере социально-гуманитарного знания (Никонов 1974).

Противоречивость смешанной (или «спутанной», по классификации Э. Эриксона) идентичности личности и общества вполне убедительно может быть раскрыта в контексте теории установки отечественного философа и психодога Д. Н. Узнадзе. Этот аспект интересен с точки зрения затухания невостребованных установок восприятия, оценки и поведения индивида или сообщества в социально-историческом пространстве, а также оживления, то есть актуализации тех установок, которые, будучи до определенного времени невостребованными, проявдяются как новообретенные и действующие в пространстве наличной культуры. Примечательно, что в кризисных условиях установки, дающие сбой, не исчезают, а переходят на своего рода «второй план сознания» и второй план социального бытия, то есть план накопления для раскрытия в контекстной ситуации (Узнадзе 2001).

Что касается негативной идентичности, выделяемой в социодогической классификации Э. Эриксона, то это и есть то самое сверхкритическое проявление подросткового максимадизма, не позводяющее зачастую под воздействием внешних, воспитатедьных факторов выработать индивиду иди сообществу собственную, относительно оригинальную и ответственную позицию в отношении общества, цивилизации, культуры.

Э. Эриксон именно через установки трудного возраста рассматривает вопросы социальной, в том числе исторической, идентичности. Он подчеркивает социальную родь негативной идентичности (предложенной в качестве одного из элементов идентификационной системы), которая способствует окончательному разрушению прежних идентификационных моделей и содержательных векторов самоидентификации.

Сдедует подчеркнуть особо, что когда речь у Э. Эриксона идет о непрерывности дичностного существования во времени и пространстве, видится 
вполне справедливым вспомнить концепцию ментальных разрывов в русской истории, некоторые существенные (в плане самоопределения человека и общества) аспекты которой рассматривались ранее (Полежаев. Аичность... 2018). Индивидуально-личностные смысдовые разрывы ментальности в краткой истории видятся здесь также вполне допустимыми, и не менее, а даже более трагическими для самоопределения и развития.

Личность в историческом пространстве ментальных разрывов чаще всего погибает, если речь идет об устойчивой системе установок индивида, способствующей самоопределению, самоорганизации и принятию конкретных решений вне изменяющегося исторического контекста. История развития гражданственного общества и вообще идеи гражданственности в России напоминает нам своими примерами о возможных направлениях движения русской цивилизации в начале XIX века (Полежаев 2007). Именно «традиционная национальная культура, национальный характер и ментадитет, - подтверждает мысдь автора В. А. Ядов, - обладают высокой устойчивостью, тогда как социадьные институты в классическом их понимании, напротив, законодательно утверждают нормы и правила, наиболее соответствующие реалиям данного, скажем бытийного, пространства нации» (Ядов 2014:49). Таким образом, во взаимодействии «внешнего» и «внутреннего», «социального» и «дичностного», «витального» и «ментального» (здесь имеется в виду инертная составдяющая ментадитета / ментадьности) именно внутреннее самоопределение выступает как сущностный компонент. Это касается в полной мере и идентификационных процессов, фиксирующих установки сознания субъекта.

По всей видимости, негативная идентичность и проявляется наиболее явственно в ситуации ментальных разрывов, когда собственные установки и ценности уже не воспринимаются в качестве собственных, органично выстроенных. В этом случае происходит в некотором роде ценностный дискомфорт и, далее, ментальный срыв, стресс, когда ценностный диссонанс и на функциональную часть ментальности дичности, социальной группы, менталитета общества или государства в целом. Несоответствие социальных реалий их внутреннему образу, выработанному у индивида и принятому как правильное видение, сформированное ранее под вдиянием семьи, ближайшего социального окружения, с одной стороны, ведет к личностному кризису, с другой - это возможность, даже своего рода инструмент, позволяющий избавиться от прежней идентичности для обретения новой.

В таком ключе понимания социологического соотношения дичностносоциальных факторов формирования индивида справедливо признать, что негативная идентичность выступает своего рода защитным механизмом от саморазрушения дичности. Негативная для социального развития, она одновременно позитивна для дичностного саморазвития человека и, таким образом, дия социиального прогресса в целом.

В социологии Э. Эриксона справедливо отмечена историческая обусловленность формирования и эводюции идентичности: «Каждая человеческая жизнь начинается на конкретной эволюционной стадии и конкретном 
уровне традиции, неся в свое окружение определенный запас форм поведения и энергии, которые используются для роста и врастания в социальный прогресс. Каждое новое существование принимается в доно жизненного стиля, выработанного и интегрированного традицией, и в то же время дезинтегрируемого, - и в этом также проявляется природа традиции» (1996). Внутренняя противоречивость исторической идентичности дичности и сообщества связана, на взгляд автора статьи, прежде всего, с открытостью витальных феноменов, в которых данная конкретная дичность иди сообщество саморазвертываются, витальных, в том числе социальных, элементов и структур в феномене как социального, так и ментального плана, обладающих относительной устойчивостью в некотором временно́м протяжении.

Но в этом социально-историческом пространстве Э. Эриксон уделяет наибольшее внимание, к сожалению, исключительно психологической компоненте идентификационных актов и процессов, что понятно, поскодьку речь в его концепции идет о личностно-социальном становлении индивида. Говоря о доверии / недоверии человека к окружающей его социальной среде как базисной характеристике дичности, о передаче так называемых вечных ценностей и традиций от поколения к поколению. Такое понимание исторической идентичности в социологическом кдюче характерно для работ социально-психологического и этнопсихологического планов.

Впрочем, Э. Эриксон, отходя в ряде мест от исключительно психодогического понимания идентичности, соглашается с тем, что конкретное историческое время (а личностная идентичность также включена в темпорадьное пространство человеческой цивидизации) предлагает индивиду конкретные правила и образцы поведения, которые могут быть успешными, то есть принятыми и усвоенными в процессе идентификации в качестве, по меньшей мере допустимых. В условиях тоталитарного мироустройства общества и государства модели поведения могут навязываться как единственно возможные; и тогда речь может идти о направленных ментальных трансформациях человека. В любом случае здесь важно соотнесение удовлетворенности этим состоянием со стороны дичности / общества или эпохи в той или иной социальной пропорции.

Примечательно, что даже сторонники и приверженцы концепции социальной идентификации индивида Э. Эриксона отмечают, что анализ феномена идентичности, взятого в историческом протяжении, убедительно рассматривается в контексте ментадьного подхода к вопросам взаимодействия личности и общества- социально-культурных установок менталитета перерабатывается соответствующий набор или багаж установок культуры, автоматически осуществляющихся в данное конкретное время в конкретных социально-культурных условиях.

Точки пересечения «Я» - «Мы», «общество» - «дичность», «содержание» «форма» и другие социологические, социально-философские и психологические экстремы методологического плана определяют наиболее общие характеристики механизма осуществления исторической идентичности как на 
индивидуально-личностном, так и на коллективно-групповой, социальнокультурном и иных уровнях.

Подчеркивая разнообразие толкований и трактовок идентичности как социологического и культурно-исторического феномена, необходимо привести определение И. Ю. Николаевой, предлагающей рассматривать историческую идентичность, как «систему установок дичности» (2014:116). В этом определении, впрочем, виден тот же самый психологический уклон толкования природы идентичности, который видится однобоким и метододогически недостаточным с точки зрения понимания идентичности индивида и сообщества как исторического, гражданского или социального феномена.

Социологический аспект идентичности подчеркивается и тем, что нервный срыв индивидуально-личностного плана не позволяет продолжать прерванную навязанной остановкой деятельность, в том числе жизненно существенную, он важен для социально-культурного самоопределения индивида в любом случае, тем более, в идентификационном плане; но не менее важен он и для социально-исторического самосознания личности. Как ранее уже отмечалось (Полежаев 2007), самосознание индивида это всегда попытка взглянуть на самого себя как бы со стороны, глазами другого человека и социальной среды.

Сопоставление внешнего и внутреннего представляется нам как важнейший акт самосознания индивида. Причем внешнее рассматривается не само по себе, в раз и навсегда заданном значении, звучании и понимании, а через призму внутреннего - набора личностных характеристик и показателей субъективного (в том числе субъектного) плана. Внутреннее также рассматривается не само по себе, в некритически заданном - неизменном смысле: оно транслируется через внешнее, учитывает особенности социальной среды, которые здесь выступают в виде факторов объективного плана. Такого рода социологически смыслозначимое самоопределение сознания индивида и выступает в качестве методологической основы индивидуадьного самосознания.

Такого рода социологическое понимание самосознания как особого феномена приложимо и к социальным феноменам «большого порядка», в том числе с точки зрения вопроса взаимодействия общества и государства, дичности и общества и т. п. В. А. Ядов в свое время вспоминал в таком контексте мысль А. Грамши о том, что в Западной Европе при ослаблении государства активно проявляется в плане осуществления власти гражданское общество, развивается самоуправление, а в России при разрушении государства рушится все (2014:48).

Такого рода социологическая оценка актуальности ментальных исследований важна с точки зрения обоснования ментадьного подхода к проблемам взаимодействия общества и человека в пространстве социадьногуманитарного знания. Но ментальное - не есть исключительно психологическое. Одной лишь психологической компоненты в историческом протяжении видится недостаточно с точки зрения социального самоопределения индивида и сообщества. Ценностные ориентации, социальные нормы 
и правила, императивы и запреты выступают как своего рода опорные точки конкретного социального пространства или рубежа цивилизации, но не как абсолютные ориентиры, измерители социальной направленности деятельности эпохи.

Социологическое и социально-фидософское осмысление исторической идентичности, даже в психологическом контексте, не может, конечно, не включать в себя некоторые элементы экзистенциального философствования для отражения объективного духа (в формальном и реальном его измерении) определенной исторической эпохи - через эмоции и переживания людей (вообще или конкретных исторических персонажей) в тот или иной исторический период.

Вместе с тем только внутренней самооценки, рефлексии для основательного и объективного анализа недостаточно (если только это вообще возможно), тем более, если он окрашен эмоциональными тонами. Именно в этом смысле видится необходимым взгляд со стороны, даже если он тенденциозен, сверх-критически ориентирован и несправедлив.

Закдючая данное социодогическое исследование, следует привести в подтверждение мысди автора статьи слова Э. Ю. Соловьева, утверждавшего о недостаточных возможностях отдельного индивида в плане самодетерминации собственного образа мыслей, чувств, поведения. Человеку в дюбом случае необходимо не просто сопоставление себя с окружающими, но и стороннее суждение. «Это справедливо, - замечает он, - не тодько для сознания отдельных людей, но и для сознания наций, вероисповедных общностей, политико-идеологических движений» (1991:3). Действительно, самосознание как исторически сформированная потребность возрастает в сопоставдении с иными точками зрения, пусть даже они высказаны не в конструктивном плане, а в виде национально-культурных ярлыков, накопившихся исторических обвинений и обид.

Рассмотренный социологический аспект осмысления исторической идентичности / самоидентификации человека, социальной группы и большого сообщества людей видится весьма интересным и требует отдельного заинтересованного осмысления в пространстве отечественного социадьногуманитарного знания.

\section{ИСПОЛЬЗОВАННЫЕ ИСТОЧНИКИ}

1. Барг, М. А. Эпохи и идеи: становление историзма / М. А. Барг. - М.: Мысль, 1987. - 348 [2] c.

2. Гуревич, А. Я. Исторический синтез и Школа «Анналов» / А. Я. Гуревич; ИВИ РАН. М.: Индрик, 1993. (Сер. «Научная библиотека студента. История»). - 328 с.

3. Идентификация / Этнопсиходогический словарь / под ред. В.Г. Крысько. - М.: Изд-во МПСИ, 1999. - С. 72.

4. Данилюк, А. Я. Концепция духовно-нравственного развития и воспитания дичности гражданина России / А. Я. Данилюк, А. М. Кондаков, В. А. Тишков. - М.: Просвещение, 2009. 24 с. (Сер. «Стандарты второго поколения»).

5. Московичи, С. Век толп / С. Московичи. - М.: Центр психологии и психотерапии, 1996. - 447 c. 
6. Николаева, И. Ю. Идентичность / И. Ю. Николаева // Теория и методология исторической науки. Терминологический словарь / отв. ред. А. О. Чубарьян. - М.: Аквилон, 2014. - 576 с. (Сер. «Образы истории»). - С. 115-119.

7. Никонов, К. М. Свобода и ее содержание // Свобода и ее содержание / под ред. К. М. Никонова. - Волгоград: Изд-во ВГПИ, 1974. - С. 3-101.

8. Полежаев, Д. В. Аичность и тоталитаризм: ментальные трансформации: монография / Д. В. Полежаев. - М.: Планета, 2018. - 208 с.

9. Полежаев, Д. В. Русский менталитет: социально-философское осмысление: монография / Д. В. Полежаев; ВГИПК РО. - Волгоград: Изд-во ВолГУ, 2007. - 370 с.

10. Полежаев, Д. В. Субъектный подход в измерении качества образования: философскометодологические основы / Д. В. Полежаев // Primo aspectu. - 2018. - № 3 (35). - С. 35-42.

11. Резник, Ю. М. Человек и мир: грани со-бытия / Ю. М. Резник // Аичность. Культура. Общество. - 2014. - Т. XVI. - № 3-4 (83-84). - С. 66-82.

12. Соловьев, Э. Ю. Прошлое толкует нас: очерки по истории философии и культуры / Э. Ю. Содовьев. - М.: Политиздат, 1991. - 432 с.

13. Стратегия развития воспитания в Российской Федерации на период до 2025 года. Распоряжение Правительства Российской Федерации от 29 мая 2015 г. № 996-р. г. Москва.

14. Узнадзе, Д. Н. Психология установки / Д. Н. Узнадзе. - СПб.: Питер, 2001. - 416 с. (Сер. «Пихология-киассика»).

15. Эриксон, Э. Идентичность: юность и кризис / Э. Эриксон / общ. ред. и предисл. А. В. Толстых; пер. с англ. А. М. Прихожан, В. И. Ривош, А. Д. Андреева. - М.: Прогресс, 1996. - 344 с.

16. Ядов, В. А. Трансформация постсоветских обществ: что более значимо - исторически традиционное или недавнее прошлое / В. А. Ядов // Социологические исследования. - 2014. № 7. - С. 47-50. 